\title{
Greenhouse production of nectarines for early harvest in France: a cultivation system with shallow rest or no rest
}

\author{
P. Balandier and R. Rageau
}

Laboratoire de Bioclimatologie, INRA, Domaine-de-Crovelle, 63039 Clermont-Ferrand Cedex, France

\section{Introduction}

The greenhouse cultivation system was started in France 5 yr ago. The aim of this system was to supply the market with peaches earlier than the southern European countries do already. Although the current system (modified 'Bellini system') has had favorable economic results, the environmental conditions were determined empirically and are probably not optimal. The feasibility of heating the greenhouse earlier or increasing the temperature is often questioned but, unfortunately, there is a lack of basic knowledge about tree physiology, especially in experiments such as this one which involves the severe cutting back of the trees in summer.

Arias and Crabbe (1975) studying cherry trees, Barnola and co-workers (1976) studying hazelnut trees and Dreyer and Mauget (1986) studying walnut trees found that buds on shoots or parts of shoots which started growing as a result of severe summer pruning or water stress never reached a high level of dormancy. Erez (1987) carried out a similar experiment on peach trees grown under forced conditions in Israel, but looked more closely at bud development: these particular buds seemed to experience a low level of dormancy; however, this approach was rather indirect. A first study on nectarine trees grown in a greenhouse was carried out by Rageau and Ridray (1989), with the following conclusion: no dormancy in the leaf buds and slight dormancy in the flower buds. These conclusions still have to be confirmed, especially for the flower buds.

\section{Materials and Methods}

Experiments were carried out with 3 yr old nectarine trees (cv Armking grafted onto peach rootstock 'GF 305') which had been 'classically' trained in containers for greenhouse production (Rageau and Ridray, 1989). In June 1987, after the May harvest, 3 of the trees were taken outside; they were not cut back (treatment 0 ); in August, these trees suffered a brief, but severe water stress. The other treatments were: G: 4 trees were kept at a low temperature until January 18 th and then afterwards at a temperature above $15^{\circ} \mathrm{C} ; \mathrm{G} / 0: 3$ trees were taken outside on November 20th; $H_{1,10}$ and $H_{1,15}$ : on December 22nd, 4 trees were put into temperature-conditioned boxes $\left(2\right.$ at $10^{\circ} \mathrm{C}, 2$ at $\left.15^{\circ} \mathrm{C}\right)$ and then they were put back into the greenhouse on January 18th; $H_{11,10}, H_{\| 1,18}$ and $H_{11,20}$ : 
on January 18 th, 6 trees were put into temperature-conditioned boxes $\left(2\right.$ at $10^{\circ} \mathrm{C}, 2$ at $18^{\circ} \mathrm{C}$ and 2 at $20^{\circ} \mathrm{C}$ ) and then put back into the greenhouse on January 28th for $H_{11,20}$ and on February 4 th for $\mathrm{H}_{11,10}$ and $\mathrm{H}_{11,18}$.

The leaf bud growth capacity was worked out using the 'one node cuttings' method; it was quantified by the arithmetic mean (mean time of bud burst, MTB) of the individual burst time lapse under normal conditions, using a sample of about 100 buds on 20 shoots, for each sampling date.

From 15 shoots about 100 flower buds were sampled, from which floral primordia were removed and immediately weighed. The mean weight $(W)$ of the fresh bud and the corresponding logarithm $(L W)$ were calculated for each sampling date. A number was given to each segment representing the growth between two dates plotted in Fig. 2; the slope $\alpha$ of each segment (relative growth rate during this period) and the mean temperature $(T)$ were calculated. On the trees, at the end of the experiments, using a large sample (about 500) each leaf bud was recorded as 'burst' or 'not burst'.

\section{Results}

\section{Growth capacity of leaf buds (Fig. 1)}

For all considered treatments, the registered MTB values never reached the 'peak' values generally recorded for peach trees under normal cultivation conditions $(>700 \mathrm{~h})$. With the 0 treatment, there is one of two possibilities: either a 'peak' value occurred but was not recorded, for lack of suitable sampling date in October, or actually it did not occur (a possible explanation is that it is a consequence of summer water stress). With moving the trees from the greenhouse to outside (a few degrees $\left({ }^{\circ} \mathrm{C}\right)$ cooler), the MTB with the $\mathrm{G} / 0$ treatment first decreased at a more rapid rate, then afterwards at a slower rate than with the $G$ treatment.

Growth capacity of flower buds (Figs. 2 and 3)

Plotting $\alpha$ against $T$ seemed to fit a single response curve, the same as the curve drawn by Rageau (1982) with Redhaven peach trees, during the post-dormancy period. Nevertheless, for many treatments, the $\alpha$ values corresponding to the early part of the growth curves were rather low, especially with the $H_{1}$ treatments (the very low value corresponding to the segment 1 of the $H_{11,20}$ treatment seemed to stem from a sampling or a measurement condition problem).

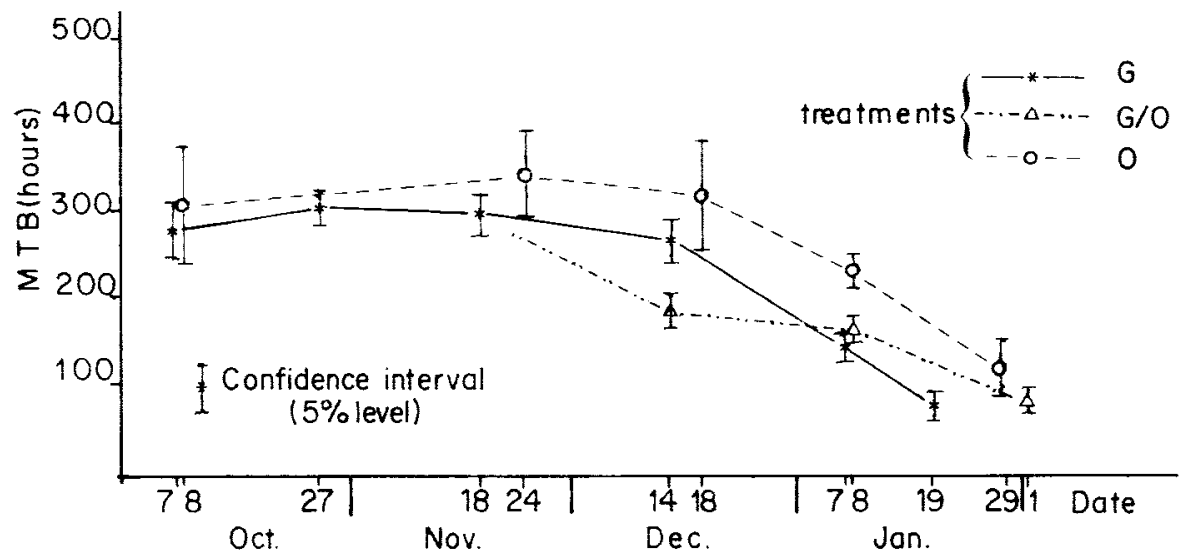

Fig. 1. Growth capacity of axillary leaf buds for 3 treatments, as expressed by the mean time of bud burst (MTB). 


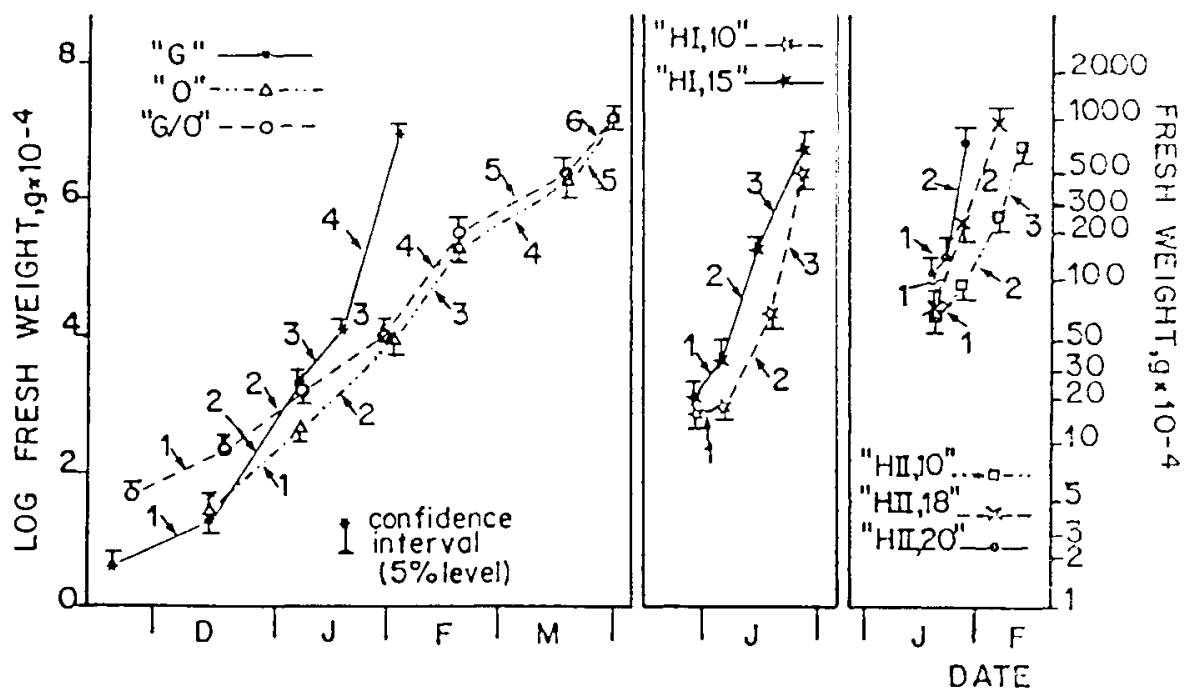

Fig. 2. Fresh weight of flower primordia for various treat.nents.

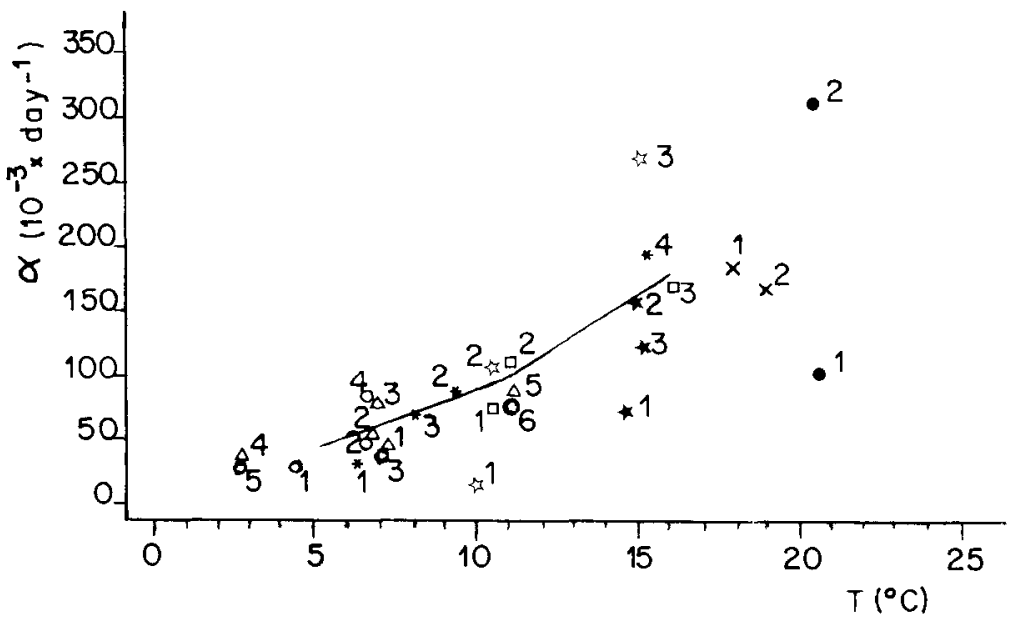

Fig. 3. Growth rate of the flower primordia as a function of temperature $(T)$; the solid limit represents the data obtained by Rageau (1982) on Redhaven during the post-dormancy period; the number correspond to the successive line segments in Fig. 2.

\section{Leaf bud breaking on the trees}

There was a difference between the bud breaking percents for the different treat- ments: G/0: $88 \%$ (a); G: $74 \%$ (b); $H_{1,10}$ : $62 \%$ (c); $H_{1,15}: 64 \%$ (c); $H_{11,10}: 77 \%$ (b); $H_{11,18}: 69 \%$ (b, c), $H_{11,20}: 76 \%$ (b) (significantly different values - $5 \%$ level - are referred to with different letters). 


\section{Discussion and Conclusion}

The buds of the nectarine trees 'classically' trained for greenhouse production experienced only a slight true dormancy which could be detected for the leaf buds by comparing the $G$ and $G / 0$ MTB curves and for the flower buds the dormancy was detected by the 'low' $\alpha$ values corresponding to the December and early January growth curves. This dormancy seemed easy to overcome, even with the $\mathrm{H}_{1}$ experimental conditions which did not lead to any problems at the agronomic level (good fruit yield). There is no definite conclusion that no problems would exist if the greenhouse were to be heated earlier; for example, differences in the leaf bud sprouting on the trees took place between the December and the January heating treatments and could be much more important with earlier heating. Further studies are needed to obtain more precise information on the ability of the buds and, more particularly the floral ones, to grow during early autumn.

\section{References}

Arias O. \& Crabbe J. (1975) Altérations de l'état de dormance ultérieur des bourgeons obtenus par diverses modalités de décapitation estivale, réalisées sur de jeunes plants de Prunus avium L. C.R. Acad. Sci. Sér. D 280, 2449-2452 Barnola P., Champagnat P. \& Lavarenne S. (1976) Taitle en vert des rameaux et dormance des bourgeons chez le noisetier. C.R. Seances Acad. Agric. Fr. 16, 1163-1171

Dreyer E. \& Mauget J.C. (1986) Conséquences immédiates et différées de périodes de sécheresse estivale sur le développement de jeunes noyers (Juglans regia L. cv (Pedro»): dynamique de croissance et de dormance automnohivernale des bourgeons. Agronomie 6, 639650

Erez A. (1987) Use of the rest avoidance technique in peaches in Israel. Acta Hortic. 199, 137-144

Rageau R. (1982) Etude expérimentale des lois d'action de la température sur la croissance des bourgeons floraux du pêcher (Prunus persica L. Batsch) pendant la post-dormance. C.R. Seances Acad. Agric. Fr. 68, 709-718

Rageau R. \& Ridray G. (1989) Nectarine cultivation in greenhouse for early harvest in France: a management system with rest avoidance. International Peach Symposium I.S.H.S., 1988, Clemson, SC, U.S.A. Acta Hortic. in press 